\title{
UM ESTUDO SOBRE O USO DA INTERNET NO CONTEXTO EDUCACIONAL BRASILEIRO
}

\section{ARTIGO ORIGINAL}

BATISTELLA, Jefferson ${ }^{1}$

VINíCIUS, Eduardo Pires ${ }^{2}$

BATISTELLA, Jefferson. VINÍCIUS, Eduardo Pires. Um estudo sobre o uso da internet no contexto educacional brasileiro. Revista Científica Multidisciplinar Núcleo do Conhecimento. Ano 04, Ed. 07, Vol. 06, pp. 27-36. Julho de 2019. ISSN: 2448-0959

\section{RESUMO}

Os avanços e a disseminação do uso das tecnologias de informação e comunicação (TIC), mais precisamente da Internet, descortinam novas perspectivas para a educação, com suporte em ambientes virtuais de aprendizagem (AVA). Considerando-se que a distância geográfica e o uso de múltiplas mídias são características inerentes à $E A D$, mas não suficientes para definirem a concepção educacional, discute-se essa modalidade tecnológica não apenas como uma solução paliativa para atender alunos situados distantes geograficamente das instituições educacionais nem apenas como a simples transposição de conteúdos e métodos de ensino presencial para outros meios e com suporte em distintas tecnologias. Dessa forma, esse trabalho tem engajamento no uso da internet no contexto educacional brasileiro, demonstrando a história da internet, a história da Educação a Distância

1 Pós-graduado em Educação Especial e Inclusiva e Neuropisicopedagogia pela FAVENI. Especialista em Metodologia do Ensino de Biologia e Química pela UNITER. Licenciado em Ciências Biológicas pela UFMT.

${ }^{2}$ Tecnólogo: Tecnologia em Segurança da Informação pela UNICESP e em Redes de Computadores pela UNEB. 
(EAD) no ensino brasileiro, que é uma realidade e um formato de ensino cada vez mais divulgado e procurado pelos estudantes, assim como as mídias educacionais conectadas no contexto atual brasileiro, que tem ajudado com ferramentas poderosas na facilitação do processo de ensino-aprendizado que acontece nas escolas e a todo tempo e em todos os lugares nesse mundo virtual e real.

Palavras-chave: Internet, Educação, ensino, aprendizagem.

\section{INTRODUÇÃO}

Nesse mundo globalizado, em que a internet das coisas está dominando, precisa-se conhecer a história para construir o presente e consolidar o futuro. Observa-se que a maioria dos estudantes brasileiros estão desmotivados e, infelizmente, não querem se dedicar aos estudos, logo, a Internet é uma ferramenta pedagógica poderosa que pode ajudar a melhorar o ensino-aprendizado.

Desta forma, se faz necessário direcionar o uso da Internet nas escolas e sensibilizar a comunidade escolar a se conscientizarem do uso inteligente e dinâmico da Internet para o crescimento intelectual, moral e cívico, individual e coletivo.

O uso da Internet com critério pode tornar-se um instrumento significativo para o processo educativo em seu conjunto. Ela possibilita o uso de textos, sons, imagens e vídeo que subsidiam a produção do conhecimento. Além disso, a Internet propicia a criação de ambientes ricos, motivadores, interativos, colaborativos e cooperativos (BEHRENS, 2008, p. 99).

A internet é uma ferramenta capaz de deixar as aulas de qualquer disciplina mais atrativas e dinâmicas, desde que o professor, também, saiba conduzir a utilização deste recurso tecnológico. Sabe-se que isso requer tempo e quebra de paradigmas educacionais, mas é necessário acreditar e agir coletivamente para que cada estudante tenha a melhor possibilidade de aprendizagem e seja cidadão proativo num país que está passando por dificuldades econômicas, políticas e sociais. 
A escola e os professores devem oferecer a seus educandos os recursos disponíveis nos seus meios. Recusar esta possibilidade significa omissão e não comprimento da missão principal do educador; preparar cidadãos proativos para um mundo cada vez mais competitivo e, infelizmente, com grandes disparidades sociais (TAJRA, 2001 p.10).

A internet é o que temos de mais tecnológico como ferramenta no contexto educacional brasileiro, portanto, essa pesquisa é atual, pois pretender realizar um estudo que visa demonstrar possibilidades de melhorias do processo de ensinoaprendizagem nas escolas brasileiras, aderindo a novos conceitos e novas possibilidades, para avanços em novas pesquisas sobre a temática abordada.

Para tanto, o trabalho está estruturado, além desta seção introdutória, em quatro seções. Na seção 2 são fundamentados os assuntos que, são bases para o entendimento do trabalho. Na sessão 3, estão descritos os materiais e a metodologia utilizado para o desenvolvimento deste. Na seção 4, são discutidos e relacionados os resultados obtidos. Ao final, na última seção, são expostas as conclusões e perspectivas de trabalhos futuros.

\section{FUNDAMENTAÇÃO TEÓRICA}

Esta seção apresenta brevemente alguns conceitos e definições que norteiam e auxiliam o entendimento do trabalho, tais como: História da Internet no Brasil, Relações entre Internet e Educação, Educação a Distância no Brasil e Mídias Educacionais Conectadas.

Utilizamos como principais fundamentadores Teóricos, os escritores: BEHRENS (2000), NASCIMENTO (2007), TAJRA (2011), HARASIM (2005).

\section{HISTÓRIA DA INTERNET NO BRASIL}

Segundo a pesquisa digital realizada em 2018 na Wikipédia, à internet chegou ao Brasil no ano de 1988, no qual o Laboratório Nacional de Computação Científica (LNCC) se conectou à Universidade de Maryland, nos Estados Unidos, por meio da 
Because it's Time of Network (BITNET) pois essa rede permitia a troca de mensagens, principalmente por iniciativa de estudantes e professores da Fundação de Amparo à Pesquisa de São Paulo (FAPESP), e juntamente com a Universidade Estadual do Rio de Janeiro (UERJ), ao ter acesso à rede da Fermi National Accelerator Laboratory (Fermilab), em Chicago e, em 1989, a Universidade Federal do Rio de Janeiro (UFRJ) também se integrou a rede BITNET, em conjunto com outra universidade americana.

No ano de 1990, surge a Rede Nacional de Pesquisa (RNP), responsável por criar a infraestrutura de rede de Internet no Brasil, e dois anos depois, 11 estados estavam interligados em uma rede de equipamentos e linhas de comunicação (RNP, 2016).

Nessa época, os acessos ao mundo virtual eram bem rudimentares, se comparado com o que ocorrem atualmente, e só nesse momento surgiam as Buletim Board System (BBS), que oferecia uma conta de e-mail e acesso à Internet de forma gratuita. No ano de 1994,, com a divulgação dos benefícios da Internet entre os estudantes das universidades e empresas privadas, na Universidade de São Paulo (USP) os discentes iniciaram desenvolvimentos de páginas web.

O Comitê Gestor da Internet (CGl) - foi criado em 1995 e recebeu a atribuição para coordenar e integrar as iniciativas relacionadas no Brasil, visando promover mais qualidade técnica e inovação.

O uso comercial da Internet no Brasil iniciou-se apenas em 1996, com o surgimento dos portais Zaz e UOL, em que o governo também entra na era da inovação e implementa a entrega do IRPF via online.

No ano de 2000, a Internet ganha o impulso para o crescimento, e os provedores gratuitos surgem para oferecer acesso para todos. É criada nesse momento a IG, que ainda usava as conexões discadas para acessar a rede. Para manter o serviço, as provedoras eram financiadas por propagandas nos navegadores, mas esse modelo se mostrou insustentável, o que causou o fechamento de várias empresas. 
A melhoria da infraestrutura de comunicações permitiu a implementação da Assymetrical Digital Subscriber Line (ADSL - Linha Digital Assimétrica para Assinante), a Internet de banda larga, que gerou um aumento da velocidade.

A popularização do acesso à Internet foi importante para o surgimento de vários serviços e sites, tanto que em 2004 ocorre o lançamento de uma das mais famosas redes sociais, o Orkut e, posteriormente, o Facebook, o que permitiu a consolidação como mídia de massa.

Segundo a pesquisa Digital in 2018, divulgada pelos serviços online Hootsuite e We Are Social, o Brasil tem atualmente 139.1 milhões de usuários, isso significa que levando em conta que a população é de 210.1 milhões de pessoas, a Internet tem uma taxa de penetração de $66 \%$, demonstrando que o país tem um alto índice de utilização, refletindo economicamente e socialmente no cotidiano das pessoas e na implantação de políticas públicas pelo Estado.

\section{RELAÇÕES ENTRE INTERNET E EDUCAÇÃO}

No contexto mundial, principalmente nos Estados Unidos, a utilização das redes para fins educacionais se inicia nos anos 1960, por meio do sistema Plato, sistema de instrução assistida por computador, para máquinas compartilhadas. Em 1969, universidades passam a utilizar redes de computadores de tempo compartilhado para oferecer aulas de matemática, cuja interação se dava por meio dos correios eletrônicos. Já nos anos 70, o e-mail passa a ser utilizado, inicialmente, para troca de informações acadêmicas e, finalmente, para complementar cursos universitários, além do ensino fundamental e médio (HARASIM et al., 2005).

Pode-se localizar o início do uso da internet no Brasil como parte de um projeto educacional, tendo em vista que o começo das atividades dessa rede ocorreu, em 1988, por iniciativa da FAPESP, da UFRJ e do LNCC. Posteriormente, em 1989, foi realizada uma interligação inicial entre instituições de ensino de 11 capitais diferentes, por meio da Rede Nacional de Pesquisas, criada pelo Ministério da Ciência e Tecnologia, processo que deu origem à implantação comercial da Internet no Brasil. 


\section{EDUCAÇÃO A DISTÂNCIA NO BRASIL}

Atualmente, é impossível pensar na questão da Internet como recurso educacional sem pensar na terminologia Educação a Distância, conceito hoje largamente utilizado e que representa um formato de ensino cada vez mais procurado pelos estudantes. Entende-se, portanto, a EAD como:

uma modalidade de ensino que funciona através de um processo educativo sistemático e organizado que tem como característica fundamental a separação físico-espacial entre professores e alunos, que interagem de lugares distintos, através de meios tecnológicos diversos, que possibilitam uma interação bidirecional, ou seja, uma interação de dupla via. (LIMA, 2012, p. 24)

Embora hodiernamente essa modalidade pedagógica esteja mais associada ao uso de computadores e da Internet, sua origem remete a qualquer tipo de ensino que seja assíncrono. Ainda nos anos 20, no Brasil, o nome do radialista Roquette Pinto chama atenção por seu pioneirismo no formato de educação a distância via rádio. Em 1923, ofertava, por meio da Rádio Sociedade do Rio de Janeiro, cursos de ciências humanas como Língua Portuguesa, Francesa e suas literaturas, bem como curso de Telefonia e Radiotelegrafia. Em 1934, instala a Rádio Escola Municipal no Rio, no qual "os estudantes tinham acesso prévio a folhetos e esquemas de aulas", além de "correspondência para contato com os estudantes" (ALVES, 2018, p. 88).

Nos anos 40, surge o Instituto Universal Brasileiro, ofertando cursos profissionalizantes e, ainda nessa década, surge a Universidade do Ar, patrocinada pelo SENAC e pelo SESC, com cursos comerciais radiofônicos. Nos anos 1960, a Igreja Católica produziu cursos voltados para a alfabetização daqueles que estavam excluídos do sistema de ensino presencial, veiculando aulas por meio do rádio, no chamado Movimento de Educação de Base, pioneiro na democratização do acesso à educação e no letramento de jovens e adultos. 
Como projeto nacional, apenas em 1970 foi criado o Projeto Minerva, convênio entre o Ministério da Educação, a Fundação Padre Landell de Moura e a Fundação Padre Anchieta, utilizando também o rádio para a educação e a inclusão social de adultos, que se manteve até o começo da década de 80. Em 1976, cria-se o Sistema Nacional de Teleducação, com cursos ministrados por meio de material instrucional e, finalmente, em 1979, a Universidade de Brasília se torna a pioneira na Educação a Distância no ensino superior, produzindo cursos por meio de jornais e revistas, transformando-se, em 1989, no Centro de Educação Aberta, Continuada, a Distância.

O período de 1990 é crucial, pela evolução e pela afirmação da educaçãoa distância como modalidade de ensino, tornando-se um campo de ensino de abrangência e credibilidade a partir de 1995, com a comercialização da Internet. Em 1992, é fundada a Universidade Aberta de Brasília, marco importante desse formato educacional no Brasil, e, em 1996, cria-se a Secretaria de Educação a Distância, do Ministério da Educação, com foco numa política de ensino que privilegie a democratização e qualidade da educação brasileira. No mesmo ano, a Educação a Distância passa a existir de modo oficial, sendo regida e inclusa na Lei de Diretrizes e Bases da Educação Nacional.

Nos anos 2000, por meio de um contrato entre 70 instituições públicas do Brasil, forma-se a UniRede, que passa a oferecer cursos de graduação, pós-graduação e extensão. O MEC começa a implantar, a partir de 2004, diversos cursos de formação inicial e continuada para professores da rede pública, culminando na formação do Sistema Universidade Aberta do Brasil, marco na unificação, profissionalização e amplitude do ensino a distância, público no Brasil.

\section{MÍDIAS EDUCACIONAIS CONECTADAS}

O advento da comercialização da Internet no Brasil, que se expandiu de modo vasto nas duas décadas do século XXI, demonstrou o alcance desse recurso para além do uso puramente comercial, alcançando milhões de residências em todo o país. Dados do Instituto Brasileiro de Geografia e Estatística (IBGE), do ano de 2018, mostram que $64,7 \%$ de toda a população do Brasil está conectada à rede, o que corresponde a 116 
milhões de pessoas conectadas. No que se refere à contagem de domicílios com acesso online, esse número corresponde a quase dois terços das residências brasileiras, o que explicita uma realidade de acesso irrestrito à Internet, que vai além do simples uso em empresas e universidades, embora essa abrangência esteja relacionada à estratificação social, na qual as residências das classes $D$ e $E$ ainda estão distantes.

Essa ubiquidade da Internet em todos os espaços sociais, dos mais coletivos aos mais domésticos, faz refletir sobre seus usos não apenas no ambiente educacional tradicional, como as escolas e universidades, mas como ferramenta que permita o aprendizado assíncrono, mas expandido para além dos limites conservadores. Dessa forma, cabe apresentar e discutir recursos que podem ser utilizados não só na plataforma da Educação a Distância, mas também de modo individual, como propulsor de aprendizagem e conhecimento, bem como repensar o papel do professor nessa situação atual, em que não é mais o detentor único do conhecimento e deve disputar espaço, ou se realocar, em meio à amplitude de informações.

No que tange ao papel do docente, talvez a principal questão esteja em entender o papel do educador, na atualidade, como mediador do conhecimento, de forma a dirimir a "confusão entre informação e conhecimento", pois "o conhecimento não se passa, mas cria-se e constrói-se" (NASCIMENTO, 2007, p. 73). Portanto, o docente deve agir no sentido de conscientizar os estudantes para a construção de um conhecimento a partir da seleção de informações relevantes, que construam pontes entre o mundo real e o saber acadêmico. Orientar e fazer da internet uma ferramenta produtiva de pesquisa é a base do conhecimento hodierno, indo além, da simples cópia de textos retirados da web. Assim:

o educador deve estar preparado para ajudar os educandos a localizar conteúdos de qualidade e a transformar os textos pesquisados em conhecimentos úteis, em material de debates e reflexões, em leitura crítica, lembrando que a internet não é a única fonte de pesquisa a ser utilizada. (NASCIMENTO, 2007, p. 74). 
Em 1993, numa pesquisa realizada nos Estados Unidos, sobre a utilização da rede de computadores no contexto educacional, dentre as características positivas oriundas dessa experiência, os educadores e estudantes citaram as seguintes mudanças: a mudança do papel do professor, que se torna facilitador e mentor; os alunos tornamse participantes ativos, tornando as discussões mais aprofundadas; houve um aumento significativo do acesso a recursos; os estudantes se tornaram mais independentes e passaram a ser o centro do ensino, de forma que a aprendizagem segue um ritmo individualizado, dentre outros pontos (HARASIM et al., 2005).

\section{MATERIAIS E MÉTODOS}

Esta pesquisa consiste na pesquisa exploratória a partir do levantamento bibliográfico das publicações teóricas e científicas acerca do tema de Internet no Contexto Educacional Brasileiro.

A pesquisa exploratória, conforme Gil (1999) visa proporcionar maior familiaridade com o problema com vistas a torná-lo explícito ou a construir hipóteses. De forma semelhante Mattar (2001), considera que os métodos utilizados pela pesquisa exploratória são amplos e versáteis. Os métodos empregados compreendem: levantamentos em fontes secundárias, levantamentos de experiências, estudos de casos selecionados e observação informal.

Portanto, no tópico a seguir são apresentados alguns estudos em que a Internet é aplicada na Educação.

\section{RESULTADOS E DISCUSSÃO}

É inegável que a Internet produz novas relações educacionais que, de certa forma, facilitam a tarefa atual do professor, permitindo ao estudante "um contato mais direto com o mundo, o que atende a mais uma necessidade atual: o da experiência direta como modalidade de aprendizagem mais propícia ao desenvolvimento da capacidade de resolução criativa de problemas" (SOBRAL, 1999, p. 15). 
Há, no entanto, aspectos negativos que merecem ser ressaltados, como o fato de ser mais trabalhoso preparar aulas nesse modelo, além da necessidade dos estudantes terem mais compromisso com as datas e participarem mais ativamente (HARASIM et al., 2005). Essas preocupações não são, no entanto, empecilhos ao uso da internet como ferramenta educacional eficaz, mas etapas que precisam ser vencidas. Como qualquer outra modalidade de ensino, "questões importantes precisam ser consideradas, como quais são as tecnologias de rede apropriadas, como integrar o trabalho em rede ao currículo, como "ensinar" e "aprender" em rede e como transformar a rede num ambiente educacional eficaz" (HARASIM et al., 2005, p. 36).

Contemporaneamente, há uma infinidade de recursos e aplicativos via web que podem ser usados como ferramenta principal e/ou acessório no processo de ensinoaprendizagem. Em primeiro lugar, os sites dão acesso a variadas formas de mídia, que podem ser utilizadas como fonte de pesquisa, além da possibilidade de utilizar a construção de páginas web como processo educacional, ao reunir a pesquisa de conteúdo e os conhecimentos de informática em uma só atividade. Há, ainda, o envio e o recebimento de arquivos (download e upload) tanto por e-mail, quanto por plataformas de conteúdo ou redes sociais, além da tecnologia peer-to-peer, que reúne endereços para acesso dos mais diferentes e múltiplos conteúdo. O chat ou a sala de bate-papo, como plataforma síncrona, foi, hoje, praticamente substituída pelo WhatsApp e seus grupos, que servem para as mais diversas trocas de informação.

Outrora chamadas de listas de discussão, os espaços virtuais atualmente chamados de fóruns reúnem pessoas com os mesmos interesses e objetivos, de forma assíncrona, integrando e compartilhando conteúdo. Mesmo que distante do seu auge, blogs ainda resistem como formas simplificadas, por meio de templates, de sites de conteúdo, criando espécies de listas de discussão em seus comentários.

Apesar de todos esses recursos, talvez os mais operacionais nos dias de hoje são os smartphones que reúnem, em apenas um celular, todas as informações e multimídias possíveis, com texto, música, vídeo, fotos e aplicativos que permitem a consulta e a pesquisa nos mais variados tipos de conteúdo. Embora muitos educadores ainda se amedrontem do uso do celular no ambiente escolar, ele pode ser utilizado como 
importante ferramenta em sala de aula, por meio da instalação de programas que contêm dicionários, jogos matemáticos, quiz de disciplinas, calculadoras, mapas, dados estatísticos, meteorológicos e climáticos, notícias atualizadas, fatos históricos, biblioteca virtual de diferentes áreas.

São, portanto, infinitas as opções de ensino por meio da internet e seus recursos adjacentes, que estão modificando indelevelmente os papéis educacionais, a estrutura escolar tradicional e a forma de acesso ao conhecimento. É, logo, necessário que se repensem as atividades e os planejamentos pedagógicos de modo a integrar esses recursos a uma formação educacional mais dialógica e atual, que traga a educação para o século XXI, não ignorando as ferramentas antigas, mas atualizandoas e localizando-as em meio a espaço-tempo com mudanças constantes.

\section{CONCLUSÕES E SUGESTÕES}

Diante das inúmeras dificuldades que o país enfrenta, não é possível desistir da educação e, por isso, é necessário utilizar os recursos tecnológicos que existem, a Internet é sem dúvida uma das ferramentas multidimensional e interdisciplinar e pode ser utilizada para facilitar o ensino aprendizado de qualquer área do conhecimento.

A Internet é o que te-se de melhor como ferramenta educacional tecnológica, em que o professor é o mestre que pode conduzir uma forma inteligente, racional e dinâmica de utiliza-la em cada aula, deixando seus estudantes preparados para o mercado de trabalho, carente de profissionais que saibam utilizar à internet para fonte de conhecimento, trabalho e pesquisa.

Analisando-se os conhecimentos e conceitos aprendidos nessa pesquisa bibliográfica, afirma-se que o contexto educacional está tendo mudanças e a utilização da Internet é uma realidade em todos os níveis educacionais, no ensino fundamental, ensino médio e superior, tornando as aulas de várias disciplinas mais atrativas e dinâmicas. 
No futuro sabe-se que a Internet das Coisas vai assumir, mas no presente esta poderosa ferramenta, a Internet, é um marco no contexto educacional brasileiro e mundial.

\section{REFERÊNCIAS}

ALVES, Lucineia. Educação a distância: conceitos e história no Brasil e no mundo. Revista Brasileira de Aprendizagem Aberta e a Distância, v. 10, 2011. Acesso em 09 de dezembro de 2018.

BEHRENS, Marilda Aparecida. Projetos de aprendizagem colaborativa num paradigma emergente. MORAN, José Manuel; MASETTO, Marcos Tarciso.In: Novas Tecnologias e Mediação Pedagógica- 6ª Ed. Campinas-São Paulo: Papirus, 2000.

BRASIL Escola. Internet no Brasil e sua administração. Disponível em: <https://brasilescola.uol.com.br/informatica/internet-no-brasil.htm>. Acesso em 09 de dezembro de 2018.

GOMES, Helton Simões. Brasil tem 116 milhões de pessoas conectadas à internet, diz IBGE. Disponível em <https://g1.globo.com/economia/tecnologia/noticia/brasil-tem-116-milhoes-depessoas-conectadas-a-internet-diz-ibge.ghtml>. Acesso em 09 de dezembro de 2018.

GIL, A. C. Métodos e técnicas de pesquisa social. 5.ed. São Paulo: Atlas, 1999.

HARASIM, Linda; TELES, Lucio; TUROFF, Murray \& HILTZ, Starr Roxanne. Redes de aprendizagem: um guia para ensino e aprendizagem on-line. São Paulo: Editora SENAC São Paulo, 2005.

HISTÓRIA DA INTERNET, aberto In: Wikipédia: a enciclopédia livre. Disponível em: < https://pt.wikipedia.org/wiki/História_da_Internet > Acesso em: 9 dezembro 2018. 
KENSKI, Vani Moreira. Educação e Internet no Brasil. Disponível em: <http://www.pucrs.br/ciencias/viali/doutorado/ptic/textos/Kenski.pdf>. Acesso em 09 de dezembro de 2018.

LIMA, Artemilson Alves de. Fundamentos e Práticas em EaD. Cuiabá: Universidade Federal de Mato Grosso / Rede e-Tec Brasil, 2012.

MELLO, Daniel. Mais de um terço dos domicílios brasileiros não tem acesso à internet. Disponível em <http://agenciabrasil.ebc.com.br/geral/noticia/2018-07/maisde-um-terco-dos-domicilios-brasileiros-nao-tem-acesso-internet>. Acesso em 09 de dezembro de 2018.

MULLER, Mary Stela. Julce Mary CORNELSEN. Normas e Padrões para Teses, Dissertações e Monografias. 5aㅡ edição, Londrina: Eduel, 2003.

NASCIMENTO, João Kerginaldo Firmino do. Informática aplicada à educação. Brasília: Universidade de Brasília, 2007.

OLIVEIRA, Marcos de. Primórdios da rede: A história dos primeiros momentos da internet no Brasil. Revista Pesquisa FAPESP. Ed, v. 180, 2011. Disponível em <http://nosmidia.com.br/ebook/breve-historia-da-internet/>. Acesso em 09/12/2018

RNP - Rede Nacional de Pesquisa. Nossa história. 2016. Disponível em <https://www.rnp.br/institucional/nossa-historia>. Acesso em 09/12/2018.

SOBRAL, Adail. Internet na escola: o que é, como se faz. São Paulo: Edições Loyola, 1999.

TAJRA, Sammya Feitosa. Informática na Educação: Novas Ferramentas Pedagógicas para o professor da atualidade. 3르 ed. Ver., atual e ampliada - São Paulo: Érica, 2001.

Enviado: Janeiro, 2019.

Aprovado: Julho, 2019. 